\title{
Compressibility of a 'Fat' Clay mixed with aggregates
}

\section{Doula Bouteraa ${ }^{1 *}$ and Ahmed Rouili ${ }^{2}$}

${ }^{1}$ Civil Engineering Laboratory of Applied Sciences, LGCA, University of Tebessa, Algeria

${ }^{2}$ Department of Civil Engineering, Faculty of Sciences and Technology, University of Tebessa, Algeria

\begin{abstract}
'Fat' clayey soils, containing large proportion of fines (more than $50 \%$ ) and mixture of aggregates are usually encountered as natural deposits in a high plasticity state. These soils may be used as row material after chemical or mechanical stabilization, in many earthworks applications. The clay content, the amount and size of aggregates, are known to affect the compressibility potential, and thus, the stiffness of the soil when subjected to vertical loads. In this investigation, a comprehensive oedometer testing program was conducted on reconstituted artificial samples, made of various mass proportions of kaolin, sand and gravel. The moisture content of the samples varied accordingly to the percentage of kaolin content in each series, but yielding samples of high plasticity, having the same Atterberg limits. The compressibility was characterized herein by the coefficient of volume compressibility $\left(m_{v}\right)$. The results indicate that, for this type of soils, the compressibility is much more affected by the coarser matrix (ratio of the mass percentage of the gravel to the mass percentage of sand $G / S$ ) rather than the percentage of clay content. Based on the observations made, a chart is proposed for a quick estimation of the compressibility potential of fat clays.
\end{abstract}

Keywords: Aggregates; Compressibility; Fat clays; Kaolin; Plasticity

\section{Introduction}

Most natural soils are heterogeneous, made by a mixture of various particles components, but are usually characterized by the type of materials that is predominant. 'Fat' clayey soils containing large proportions of fines (more than $50 \%$ ) and coarse aggregates, are usually encountered as natural deposits, and may be used after chemical or mechanical treatment in many earthworks applications, like for the stabilization of road shoulders, foundations for highways, unpaved roads, driveways, engineered backfill, cement-treated base, etc. Understanding the behavior of this particular type of clayey soils and quantitatively assess the effects of gradients on their mechanical behavior, remains an important issue in geotechnical engineering. Research has shown that the behaviour of soil mixtures can be significantly different from the behaviour of the individual components of the mixture, due to differences between the mechanical and chemical properties of the individual minerals, and their ensuing effects on interparticles interactions [1]. By controlling the particle size distribution, the influence of grading on the behaviour of soils could be explored.

Nocilla [2] reported that as the clay content was reduced, the behaviour changed from a typical clay mode to a transitional form between that of clays and sands. Shiptona and Coop [3] explored the effects of mixing soils of different grain sizes, covering a wide range of grindings from clayey-silts to well-graded sands and gap-graded soils, they reported that, for such soils, it would be difficult to identify the effects of structure on the mechanics since there is no unique behaviour of the soil when reconstituted, oedometer tests performed indicated that relatively small changes to the nature or quantity of the constituent particles of a soil can change the behaviour quite dramatically. Yin and Miao [4] evaluating the impacts of soil structure on mechanical behavior for natural sedimentary clays based on oedometer tests, proposed a normalized compression line to evaluate the effects of soil structure quantitatively on the compressive behavior for natural clays mixture [5].

The work described in this paper present the results of conventional one-dimensional oedometer tests conducted on artificial (reconstituted) samples, made of fine particles (kaolin) mixed with different mass proportions coarse poorly graded aggregates (sand and gravel). Various mixing combinations were analyzed to simulate the behaviour of a large panel of fat clayey soils grading. Testing artificially reconstituted soils allows to better controlling the soil grading and mineralogy, eliminating the complex effects that these might have on the mechanical behaviour of the soil, and it ensure the experimental repeatability.

\section{Materials and Methods}

\section{Materials}

Burland [6] stated that much modern soil mechanics has developed from the results of careful, comprehensive studies of the properties of remolded or reconstituted natural soils or artificial materials such as kaolinite or illite. Kaolin used in the present work, is made of clayey minerals dominated by the kaolinite, derived essentially from the alteration of Felds path alkaline and micas with a density of 2.62 . Previous research has shown that the kaolin structure possesses great advantages in many processes due to its high chemical stability and low expansion coefficient $[7,8]$. The importance of kaolin is remarkable as one of the most abundant mineral in soils and sediments, its properties are such that it interacts with other soil elements and contribute to the mechanical stability of the soils $[9,10]$. The kaoline is also known to be the least reactive clay [11].

The sand used in this work is composed of granulated silica (of rotund shape), collected from a site near Tebessa (East of Algeria), the texture of this sand vary from coarse to very coarse and exhibit no cohesion. The grain sizes distribution of this sand is presented in Figure 1. This sand has less than 5\% fine, the coefficient of uniformity $\mathrm{Cu}=$ 2.5 and the coefficient of curvature $C c=1.25$ and could be classified (Unified soil classification system USCS) as Sand poorly graded (SP).

The gravel used in the preparation of the samples is commercial gravel, made of crushed stones sized roughly between 5 and $8 \mathrm{~mm}$. This coarse material has less than $5 \%$ fines and less than $2 \%$ of impurity content. The grains sizes distribution curve of this gravel is also shown

*Corresponding author: Doula Bouteraa, Laboratoire de Génie Civil Appliqué, LGCA, University of Tebessa, Algeria, Tel: +213 212479 50; E-mail: bouteraageotech88@hotmail.f

Received June 14, 2016; Accepted June 20, 2016; Published June 22, 2016

Citation: Bouteraa D, Rouili A (2016) Compressibility of a 'Fat' clay mixed with aggregates. J Civil Environ Eng 6: 240. doi:10.4172/2165-784X.1000240

Copyright: (c 2016 Bouteraa D, et al. This is an open-access article distributed under the terms of the Creative Commons Attribution License, which permits unrestricted use, distribution, and reproduction in any medium, provided the original author and source are credited. 
in Figure 1. With values of $C u=1.25$ and $C c=1$, it could be classified (USCS) as Gravel poorly graded (GP).

\section{Samples preparation}

In order to simulate the behaviour of a large panel of 'fat' clayey soils gradations, four series of samples were prepared, corresponding to different proportions of kaolin content (50,60, 70 and 80\%), For each series, samples were made of different mass proportions of sand and gravel. The ratio $G / S$ stand for the percentage of gravel used over the percentage of sand. Table 1 summarizes the combinations considered for the production of the 10 different samples investigated. The moisture content of the samples varied accordingly to the percentage of kaolin content in each series, but yielding samples of high plasticity, having the same Atterberg limits: $L L=63.3 \%, L P=27,75 \%$ and a plasticity index IP $=35.55 \%$.

The samples are prepared by a mechanical mixer at the desired

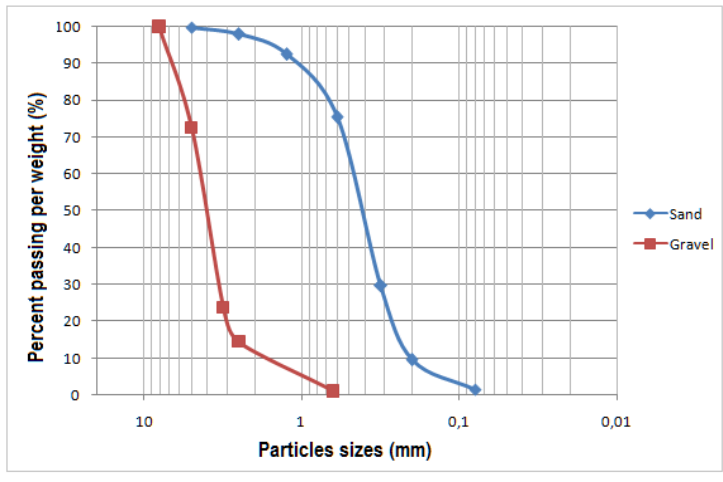

Figure 1: Distribution curves (gravel and sand).

\begin{tabular}{|c|c|c|c|c|c|}
\hline $\begin{array}{c}\text { Kaolin } \\
\text { content }(\%)\end{array}$ & Sand $(\%)$ & Gravel (\%) & $\mathbf{G} / \mathbf{S}$ & $\mathbf{W}(\%)$ & (USCS) Classification \\
\hline \multirow{4}{*}{50} & 10 & 40 & 4 & \multirow{4}{*}{17.77} & Gravelly $\mathrm{CH}$ \\
\hline & 20 & 30 & 1.5 & & Gravelly $\mathrm{CH}$ with sand \\
\hline & 30 & 20 & 0.66 & & Sandy $\mathrm{CH}$ with gravel \\
\hline & 40 & 10 & 0.25 & & Sandy $\mathrm{CH}$ \\
\hline \multirow{3}{*}{60} & 10 & 30 & 3 & \multirow{3}{*}{21.33} & Gravelly $\mathrm{CH}$ \\
\hline & 20 & 20 & 1 & & $\mathrm{CH}$ with sand and gravel \\
\hline & 30 & 10 & 0.33 & & Sandy $\mathrm{CH}$ \\
\hline \multirow{2}{*}{70} & 10 & 20 & 2 & \multirow{2}{*}{24.88} & $\mathrm{CH}$ with gravel \\
\hline & 20 & 10 & 0.5 & & $\mathrm{CH}$ with sand \\
\hline 80 & 10 & 10 & 1 & 28.44 & $\mathrm{CH}$ with sand and gravel \\
\hline
\end{tabular}

Table 1: Samples gradations and classification.

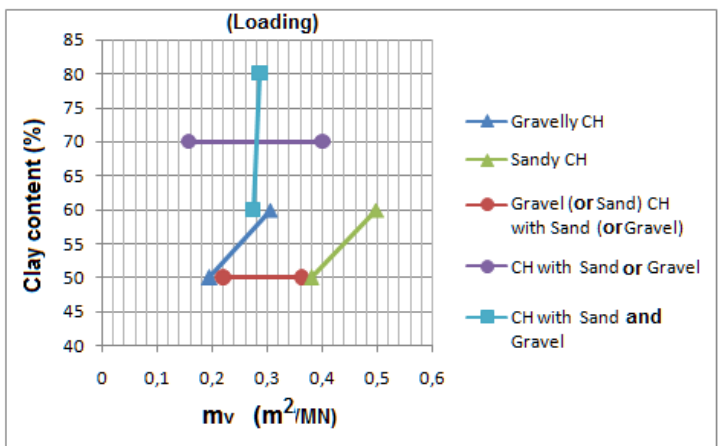

Figure 2: Variation of the average coefficient of compressibility $m_{v}$ (loading stage).

\begin{tabular}{|c|c|c|c|c|}
\hline Soil Groups & $\begin{array}{c}\text { Clay } \\
\text { content } \\
(\%)\end{array}$ & $\mathbf{G} / \mathbf{S}$ & $\begin{array}{c}\text { Average } \\
\mathrm{m}_{\mathrm{v}} \\
\text { Loading } \\
\left(\mathrm{m}^{2} / \mathrm{MN}\right)\end{array}$ & $\begin{array}{c}\text { Average } \\
\mathrm{m}_{\mathrm{v}} \\
\text { Unloading } \\
\left(\mathrm{m}^{2} / \mathrm{MN}\right)\end{array}$ \\
\hline \multirow{2}{*}{ Gravelly $\mathrm{CH}$} & 50 & 4 & 0.1951 & 0.4906 \\
\hline & 60 & 3 & 0.3042 & 0.7539 \\
\hline \multirow{2}{*}{$\begin{array}{l}\text { Gravelly (or Sandy) } \mathrm{CH} \text { with Sand (or } \\
\text { Gravel) }\end{array}$} & 50 & 1.5 & 0.2196 & 0.6109 \\
\hline & 50 & 0.66 & 0.3621 & 0.6921 \\
\hline \multirow{2}{*}{ Sandy $\mathrm{CH}$} & 50 & 0.25 & 0.3787 & 0.6742 \\
\hline & 60 & 0.33 & 0.4978 & 0.8062 \\
\hline \multirow{2}{*}{$\mathrm{CH}$ with Sand (or Gravel) } & 70 & 2 & 0.1569 & 0.7250 \\
\hline & 70 & 0.5 & 0.4007 & 0.7593 \\
\hline \multirow{2}{*}{$\mathrm{CH}$ with Sand and Gravel } & 60 & 1 & 0.2737 & 0.6210 \\
\hline & 80 & 1 & 0.2869 & 0.8015 \\
\hline
\end{tabular}

Table 2: Classification of the samples into groups.

moisture content and then remolded manually in a compaction apparatus under the same weight applied to each layer. The molding procedure of the samples was the same and carried out under the same manual weight applied. Extreme care has been taken to obtain samples of high quality, to avoid as much possible, mechanical disturbances during extrusion from the mould, trimming, and mounting of the specimens into the oedometre cell.

\section{Testing and results}

\section{Oedometer test}

Standard oedometer tests were carried out for each series to investigate the compressibility of the considered samples. The onedimensional coefficient of compressibility $m_{v}$ was explored, defined as the ratio of volumetric strain over the changes in effective stress: $\left(\Delta \varepsilon_{\mathrm{v}} / \Delta \sigma_{\mathrm{v}}\right), \Delta \varepsilon_{\text {volumetric }}=\Delta \varepsilon_{\text {vertical }}$ (du to the boundary conditions of the oedometer). Since the compression and swelling of soils are nonlinear $m_{v}$ is not constant but depends on the current stress and it is not constant (Atkinson 2007). To better evaluate the general trend of the compressibility, the different samples considered were gathered into 5 groups, according to their USCS classification as illustrated in Table 2 , where the -rerages values of $m v$ corresponding to each samples are also shown.

Figure 2 shows the variation of the average coefficient of compressibility $m_{v}$, for the loading stage, plotted against the percentages of clay content for each group of samples (Table 2). From this figure it is evident that for the Gravelly $\mathrm{CH}$ and the Sandy $\mathrm{CH}$ the compressibility coefficient increases with the percentage of clay content. For samples belonging to the following classes: Gravelly $\mathrm{CH}$ with sand, Sandy $\mathrm{CH}$ with gravel, $\mathrm{CH}$ with sand and $\mathrm{CH}$ with gravel, the compressibility seems to increase without increasing the percentage of clay content. For samples of $\mathrm{CH}$ with Sand and Gravel, the compressibility coefficient seems to be not affected by the percentage of clay content, as the compressibility remains almost constant with the increase of the clay content of the soil [12].

Figure 3 shows the variation of average coefficient of compressibility $m_{v}$, for the swelling (unloading) stage, plotted against the percentages of clay content for each group of samples. From this figure it could be stated that: for the Gravelly $\mathrm{CH}$ and the Sandy $\mathrm{CH}$ the compressibility coefficient increases with the percentage of clay content. For the samples of : Gravelly CH with sand, Sandy $\mathrm{CH}$ with gravel, $\mathrm{CH}$ with sand and $\mathrm{CH}$ with gravel, the compressibility seems slightly to increases without increasing the percentage of clay content. For samples of $\mathrm{CH}$ with Sand and Gravel, the compressibility coefficients increase with the percentage of clay content. 
The compressibility of clayey soils could be categorized following the qualitative description of the values of the average loading coefficient of compressibility $m_{v}$ shown in Table 3, proposed by Ghosh [13]. Table 4 presents the description of the different samples tested with the related qualitative description of their related compressibility.

Figure 4 shows the variation of the coefficient of compressibility plotted against the ratio $G / S$, from this figure it could be argued that, for fat clay with a proportion of $G / S$ inferior to 1 , the soil exhibit a high

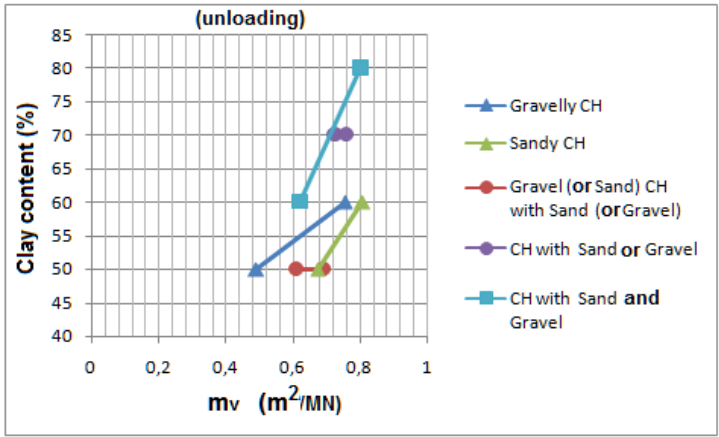

Figure 3: Variation of the average coefficient of compressibility $m_{v}$ (swelling stage).

\begin{tabular}{|c|c|c|c|}
\hline $\boldsymbol{m}_{\mathbf{v}}\left(\mathbf{m}^{2} / \mathbf{M N}\right)$ & $\begin{array}{c}\text { Qualitative } \\
\text { description }\end{array}$ & Abbreviation & Typical soils \\
\hline $0.05-0.1$ & Low compressibility & $L C$ & $\begin{array}{c}\text { Boulder, clay and very } \\
\text { stiff clay }\end{array}$ \\
\hline $0.1-0.3$ & $\begin{array}{c}\text { Medium } \\
\text { compressibility }\end{array}$ & $M C$ & Normally consolidated clay \\
\hline $0.3-1.5$ & High compressibility & $H C$ & Quick clay \\
\hline Above 1.5 & $\begin{array}{c}\text { Very high } \\
\text { compressibility }\end{array}$ & VHC & $\begin{array}{c}\text { Very organic alluvial clays } \\
\text { and peats }\end{array}$ \\
\hline
\end{tabular}

Table 3: Qualitative description of $m_{v}$ for different type of clayey soils [13].

\begin{tabular}{|l|c|c|c|c|}
\hline Soil Groups & Clay Content (\%) & $\mathbf{G} / \mathbf{S}$ & $\begin{array}{c}\boldsymbol{m}_{\mathbf{v}}\left(\mathbf{m}^{2} \mathbf{l}\right. \\
\mathbf{M N})\end{array}$ & Compressibility \\
\hline Gravelly CH & 50 & 4 & 0.1951 & $M C$ \\
\hline Gravelly CH with Sand & 60 & 3 & 0.3042 & $M C$ \\
\hline Sandy CH with Gravel & 50 & 1.5 & 0.21966 & $M C$ \\
\hline Sandy CH & 50 & 0.66 & 0.3621 & $H C$ \\
\hline CH with Gravel & 60 & 0.25 & 0.3787 & $H C$ \\
\hline CH with Sand & 70 & 2 & 0.4978 & $H C$ \\
\hline CH with Sand and & 70 & 0.5 & 0.4007 & HC \\
\hline Gravel & 60 & 1 & 0.2737 & $M C$ \\
\hline
\end{tabular}

Table 4: Compressibility description of the different samples.

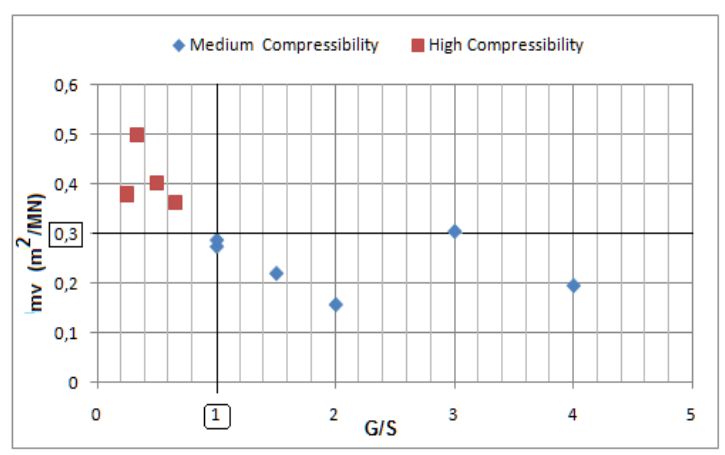

Figure 4: Compressibility chart $m_{v}$ versus $G / S$.

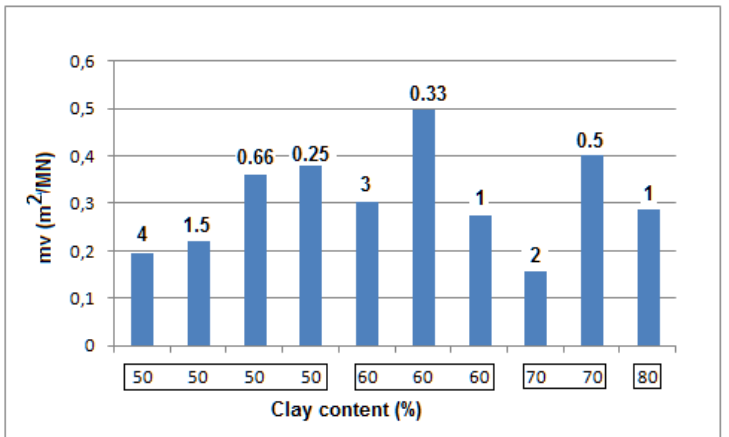

Figure 5: Compressibility charts.

compressibility, however, for fat soil with $G / S$ superior to 1 the soil exhibits a medium compressibility.

In Figure 5 the computed average values of the coefficient of volume compressibility $m_{v}$ are plotted against the corresponding sample percentage of clay content, the ratio of aggregate $G / S$ is also indicated above the corresponding sample. From this figure it could be argued that, for high plasticity fat clays, the value of the coefficient of volume compressibility $m_{v}$ is much more affected by the aggregate ratio $G / S$ rather than the percentage of clay content. For the combination of the samples considered in the present investigation, the maximum value of the coefficient of volume compressibility $m_{v}$ is obtained for the sample with $60 \%$ clay content and a ratio $G / S=0,33(30 \%$ sand and $10 \%$ gravel), classified previously as Sandy CH (Table 1 ). The minimum value of the coefficient of volume compressibility $m_{v}$ is obtained for the sample with $70 \%$ clay content and a ratio $G / S=2(10 \%$ sand and $20 \%$ gravel), classified as $\mathrm{CH}$ with Gravel (Table 1). This indicates that for the case of fat clays (more than $50 \%$ clay content) the compression behaviour is controlled by the nature of the grain matrix composition rather than the percentage of clay content. Similar observation was reported by Lupogo [14], where a transitional level of fine content was defined (30\%) above witch the author reported that the compression behaviour of the soil is controlled by the grain matrix regardless the fines types.

This observation could be of relevance since the consolidation coefficient $\mathrm{C}_{\mathrm{v}}=\left(\mathrm{k} /\left(\mathrm{m}_{\mathrm{v}} \cdot \gamma_{\mathrm{w}}\right)\right)$ is usually computed on the basis of the coefficient of volume compressibility $m_{v}$., the prediction of the compressibility of the high plasticity fat clay allows to better estimate its settlement and consolidation potential.

\section{Conclusions}

A comprehensive oedometer testing program was performed on reconstituted artificial samples, made of various mass proportions of kaolin, sand and gravel, to investigate the compressibility potential of 'fat' clays. The compressibility was characterized in this analysis by the coefficient of volume compressibility $\left(m_{v}\right)$. In order to simulate the behaviour of a large panel of 'fat' clayey soils gradations, four series of samples were tested, corresponding to different proportions of kaolin content (50,60, 70 and 80\%), For each series, samples were made of different mass proportions of sand and gravel, consequently numerous ratios $G / S$ were considered. The moisture content of the samples varied accordingly to the percentage of kaolin content in each series, but yielding samples of high plasticity, having the same Atterberg limits. The results indicates that, for this type of soils the compressibility is much more affected by the coarser matrix (ratio $G / S$ ) rather than the percentage of clay content, for the samples considered it was found that: 
1. The highest compressibility (the lowest stiffness) was encountered with sample classified (USCS) as Sandy clays of high plasticity (Sandy $\mathrm{CH})$, made of $60 \%$ of kaolin and having a ratio of $G / S=0.33$.

2. The lowest compressibility (highest stiffness) was obtained with sample of $\mathrm{CH}$ with gravel, having $70 \%$ clay content and a ratio $G / S=2$. For fat clay with a proportion of $G / S$ inferior to 1 , the soil exhibit a high compressibility (low stiffness), however, for fat soil with $G / S$ superior to 1 the soil exhibits a medium compressibility (medium stiffness).

Based on the observations made, a chart is proposed for a quick estimation of the compressibility potential of fat clays. Those observations could be of relevance since the consolidation coefficient $C_{v}$ is usually computed on the basis of the coefficient of volume compressibility $m_{v}$, the prediction of the compressibility of the high plasticity fat clay allows to better estimate its settlement and consolidation potential.

\section{References}

1. Palomina AM, Burns SE, Santamarina C (2008) Mixture of fine grained minerals kaolinite and carbonate grains. Clay and Clay Minerals 56: 599-611.

2. Nocilla A, Coop MR, Colleselli $F(2006)$ The mechanics of an Italian silt: an example of 'transitional' behaviour. Geotechnique 56: 261-271.
3. Shiptona B, Coop MR (2012) On the compression behaviour of reconstituted soils. Soils and Foundations 52: 668-681.

4. Yin J, Miao H (2013) Intrinsic compression behavior of remolded and reconstituted clays - Reappraisal. Open J Civil Eng 3: 8-12.

5. http://dx.doi.org/10.4236/ojce.2013.33B002

6. Burland JB (1990) On the compressibility and shear strength of natural clays. Géotechnique 40: 329-378.

7. http://dx.doi.org/10.1680/geot.1990.40.3.329

8. Miranda-Trevino JC, Coles CA (2003) Kaolinite properties, structure and influence of metal retention on $\mathrm{pH}$. Applied Clay Sci 23: 133-139.

9. http://www.engr.mun.ca/ ccoles/Publications/Kaol2.pdf.

10. Huertas F, Fiore S, Huertas F, Linares J (1999) Experimental study of the hydrothermal formation of kaolinite. Chemical Geol 156: 171-190.

11. Suraj G, Iyer CSP, Rugmini S, Lalithambika M (1998) Adsorption of cadmium and copper by modified kaolinites. Applied Clay Sci 13: 293-306.

12. Atkinson J (2007) The mechanics of soils and foundations. (2ndedn), Taylor \& Francis, New York.

13. Ghosh KM (2010) Foundation design in practice. Published by Asoke K Ghosh PHI Learning. New Delhi.

14. Lupogo K (2013) Effect of fines mineralogy on the oedometric compressional behavior of sandy soils. J Civil Eng Construct Technol 4: 232-238. 